\title{
Teachers' Perceptions of Inclusion in a Pilot Inclusive Education Program: Implications for Instructional Leadership
}

\author{
Zachary Y. Mngo $\mathbb{D}^{1}$ and Agnes Y. Mngo ${ }^{2}$ \\ ${ }^{1}$ Prince Mohammad Bin Fahd University, Khobar, Saudi Arabia \\ ${ }^{2}$ Andrews University, Berrien Springs, MI, USA \\ Correspondence should be addressed to Zachary Y. Mngo; zmngo@pmu.edu.sa
}

Received 16 December 2017; Accepted 13 February 2018; Published 1 April 2018

Academic Editor: Gwo-Jen Hwang

Copyright (c) 2018 Zachary Y. Mngo and Agnes Y. Mngo. This is an open access article distributed under the Creative Commons Attribution License, which permits unrestricted use, distribution, and reproduction in any medium, provided the original work is properly cited.

\begin{abstract}
The opinions of general education secondary school teachers in seven select schools involved in a pilot inclusive education program in the Northwest Region of Cameroon were sought. The findings reveal that most teachers in Cameroon still prefer separate special education institutions to inclusive ones. These conclusions contradict earlier research which showed that resistance to integrated classrooms was emanating from beliefs and customs. Teachers with some training on teaching students with disabilities and more experienced and highly educated teachers were more supportive of inclusive education indicating that resistance to the practice is linked to inadequate or complete lack of teachers' preparedness. Younger, less experienced teachers with no training in special education indicated less enthusiasm regarding the benefits of inclusion, their ability to manage integrated classrooms, and teach students with disabilities. The implication of these findings for future research, institutional support systems, institutional policies, and overall instructional leadership is discussed in this article.
\end{abstract}

\section{Introduction}

In Cameroon, the introduction of inclusion in schools as a solution to meeting the needs of students with disabilities has faced a lot of setbacks since the country's official embrace of the concept in the early 1980s. The pace of implementation of inclusive education reform has been slow despite the Cameroonian government's signing of treaties and legislation [1] aimed at promoting inclusion in all primary and secondary educational institutions. The government reinforced its commitment to promote inclusion in schools by signing the UNESCO Salamanca Statement which acknowledged that many countries, including Cameroon, had "well-established systems of special schools" for individuals with specific impairments which also could represent " a valuable resource for the development of inclusive schools" [1]. The inability to establish effective inclusive schools has not been unexpected because the policy of inclusion can only be effective if regular school teachers embrace the practice and if schools are have essential resources such as self-contained classrooms, resource rooms, trained teachers, and paraprofessionals needed to provide vital support to students grappling with learning. Indeed, many experts have suggested that the success of inclusion depends on the knowledge, instructional skills, and especially on the attitudes and beliefs of general education teachers toward the inclusion of students with disabilities $[2,3]$.

Special education is best managed when qualified teachers and related service personnel are available. This ensures proper identification, development of individualized education programs (IEPs), and their implementation and evaluation. Academic achievement for the students is better promoted when IEPs are established taking into consideration not only the degree of impairment but also the temperament, cognitive abilities, personality, and experience of the learner [4]. There are services aimed at prevention and treatment of impairments, the identification, and referral of students with special needs at the level of schools are almost absent in Cameroon [5]. The absence of training programs for special education professionals such as teachers and paraprofessionals, in tertiary educational institutions, has resulted in acute shortages of qualified personnel. 
It is not enough for teachers to have a willingness and predisposition to embrace inclusive education practices. Also, it takes more than the signing of decrees and accords by public authorities. Only a conscious and unwavering public policy of investing in the training of teachers, paraprofessionals, and in essential amenities and resources can make a difference. This study sought to find what the biggest stumbling blocks are to the functioning of inclusive schools in Cameroon, from the perspectives of the teachers regarding the concept of inclusion, benefits of inclusion, and their ability to manage inclusive classrooms and teach students with disabilities.

The first organized practice of inclusion in Cameroon, which is the source of the quantitative data used in this study, was initiated in select secondary schools involved in the SEEPD pilot inclusive education program in the Northwest Region of the country [6]. Schools in Cameroon have provided accommodation to students with disabilities, in varying degrees, depending on institutional means, mission, and vision. Most schools providing services to students with mild to moderate visual, auditory, and orthopedic disabilities since independence have been parochial schools. The Socio-Economic Empowerment of Persons with Disabilities (SEEPD) program was the first inclusive education program of its kind, involving a wide range of public schools in a region of the country.

Historical, social, and cultural factors have impacted both the treatment and education of persons with disabilities during the precolonial, colonial, and postcolonial periods in Cameroon. Several years after independence, the main education stakeholder, the government, has not treated educating students with special needs as a priority. Children or persons with disabilities are still perceived, treated, and officially labeled as "handicapped persons" and are admitted into private and government-run institutions often called "Centers for Handicapped Persons" or "Rehabilitation Centers" [5]. Despite Cameroon's signing of the Convention on the Rights of the Child, much remains to be done in the area of special education. The government does not have standards in place to handle the training of personnel working with persons with disabilities [5]. There are no established procedures for the identification and management of students with disabilities in the country's education system. Integration, which is the same as mainstreaming in the Cameroonian context, was officially embraced following the enactment of the 1983 and 1994 laws, stipulating the inclusion of students with special educational needs (SEN) in the general education classroom [1]. These legislations stipulated multidimensional support for schools, special pedagogical assistance, the training of specialized staff, and the development of curriculum materials for special education.

\section{Purpose}

The implementation of legislations on inclusive education in Cameroon has been stalled by factors that this study sought to investigate. The complicated management relationship between the government ministries involved in the training and education of persons with disabilities-Ministry of Social Welfare, Ministry of Basic Education, and the Ministry of Secondary Education-has not helped the situation. The question of which ministry is responsible for the running of what aspect of special education remains largely unanswered. Until recently, there has been a complete lack of special education programs in teacher-training colleges and an absence of a strong special education component in professional development programs in schools. Also, most schools do not have the assistive technology needed and have not been able to accommodate or modify the curriculum to cater for the needs of students with disabilities in the general education classroom [7]. A few schools, mostly Church schools, have managed to accommodate a very limited number of students with mild to moderate disabilities in the general education setting. This effort has often been carried out with very rudimentary or basic resources [6-8].

This study sought to investigate attitudes held by general education teachers toward students with disabilities in a pilot inclusive education program in Cameroon. The study also sought to know if there is any relationship between teachers' gender, age, the level of education, the number of years of teaching experience, experience teaching in the inclusive classroom, experience in teaching students with disabilities, and their attitudes toward inclusive education.

2.1. Research Questions. The study sought to answer the following:

(1) What are teachers' attitudes toward inclusive classrooms with regard to their perceptions of (a) the benefit/outcomes of integration, (b) their ability to manage integrated classroom management, (c) their ability to teach students with disability, and (d) their overall attitude toward the concept of education?

(2) Are teachers' attitudes toward inclusive classrooms affected by their (a) gender, (b) age and level of education, (c) teaching experience, (d) experience teaching in the inclusive classroom, and (e) training in special education?

(3) What are the implications of teachers' attitudes for instructional leadership at the following levels: (a) national, (b) regional, (c) intuitions, and (e) SEEPD pilot inclusive program?

\section{Method}

A quantitative nonexperimental descriptive survey research design was used in this study. Participants included 346 fulltime state-licensed general education teachers from $7 \mathrm{sec}-$ ondary bilingual schools participating in the SEEPD pilot inclusive education program in the Northwest Region of Cameroon. A survey instrument "Opinions Relative to the Integration of Students with Disabilities" (ORI) was used to collect the data used in determining the attitudes of general education teachers toward inclusion. The Statistical Package for Social Sciences Software (SPSS) was used to analyze the 
data, organize the results, and provide descriptive statistics and multivariate analysis of variances (ANOVA).

3.1. Participants. The survey was distributed to 400 teachers who were not only reachable but very willing to participate in the study. Of the convenience sample of 400 teachers who completed the survey, 348 returned their questionnaires. Due to a significant number of omissions on 2 of the 348 returned surveys, 346 scannable surveys were included in the study, representing an $87 \%$ return rate. This convenience sample represented a population of about 1200 full-time state-licensed teachers [9] in seven secondary schools involved in the SEEPD pilot inclusive education program. Of the total number of respondents, there were 182 males $(52.6 \%)$ and 164 females (47.4\%). About $68 \%$ of the surveys were completed by participants between the ages of 30 and 44 years. Results for age groups are as follows: 8 teachers (2.3\%) were aged 20 to 24 years old, $55(15.9 \%)$ were aged 25 to $29,78(22.5 \%)$ were aged 30 to $34,88(25.4 \%)$ were aged 38 to $39,71(20.5)$ were aged 40 to 44 , and $46(13.3 \%)$ were aged 45 years old and above.

Regarding the participants' level of education, 212 (61.3\%) of teachers said that they have a Bachelor's degree (DIPES I) in teaching while 126 (36.4\%) had a Masters' in teaching (DIPES II). Only eight teachers $(2.3 \%)$ had an academic Master's degree (DEA). More than half the teachers $(52.3 \%)$ had 6 to 15 years of teaching experience. Eighty $(23.1 \%)$ teachers had five years or less of teaching experience, $116(33.5 \%)$ had 6 to 10 , and $65(18.8 \%)$ had 11 to 15 years of experience. Then, $43(12.4 \%)$ had 16 to 20 years, $20(5.8 \%)$ had 21 to $25,16(4.6 \%)$ had $26-30$, and only 6 (1.7\%) had 31 years or more of professional experience.

Regarding the specific experience of teaching children with special education needs (disabilities), 185 teachers (53.5\%) said that they had experience teaching students with special education needs and 161 (46.5\%) had no experience teaching students with disabilities. Most of the teachers (81.5) said that they did not have any training on how to teach students with special needs while only $18.5 \%$ stated that they had received training in special education.

Considering that the location of the SEEPD experimental inclusive education program is in the Englishspeaking part of Cameroon, only 25 teachers (7.2\%) said that the language of instruction they used in class was French while 273 (78.9) used English as the language of instruction. On the other hand, 48 teachers (13.9\%) would use both languages interchangeably in their classrooms.

3.2. Procedures. Participants were distributed the survey during staff meetings in the presence of the researchers' representative who explained and clarified details. To initiate the process of data collection, a letter requesting the principals' permission to disseminate the surveys was sent to the Regional Delegate of Secondary Education for Northwest Region. Data collection was launched once the permission was received. All respondents in the survey received a cover letter and the survey form, which was assigned a number. Completed questionnaires were collected by the school principals and sent to the researchers via their representative. With the assistance of the researchers' representative and principals of participating institutions, the whole data collection process took about one month. At the end of the data collection, the researchers' representative shipped the completed surveys.

3.3. Instrument. The Opinions Relative to the Integration of Students with Disabilities (ORI) developed by Antonak and Larrivee [10] was used to collect data. This instrument is a revised and upgraded version of the Opinions Relative to Mainstreaming Scale created by Larrivee and Cook [11]. This earlier version of the instrument was used to investigate teachers' attitudes toward mainstreaming students with disabilities into general education classrooms. ORI is a 25 -item instrument with six possible responses ranging from $(-3)$ I disagree very much to $(+3)$ I agree very much.

The ORI was used to measure general education teachers' attitudes toward the inclusion of students with disabilities in the general education schools in the Northwest Region of Cameroon. The questionnaire is made of two sections. The first section consisted 25 items, and the second section comprises 7 demographic questions on their gender, age, level of education, years of teaching experience, experience teaching in inclusive classrooms, and training in teaching students with special needs.

The first section of the instrument has questions that require the participants to indicate their level of agreement or disagreement to the items on the 6-point Likert-type scale. Respondents were asked to choose from the following options: 1 (strongly disagree), 2 (disagree), 3 (not sure but tend to disagree), 4 (not sure but tend to agree), 5 (agree), and 6 (strongly agree).

\section{Results}

4.1. Research Question 1. Teachers' attitudes toward the concept of inclusion (COI) were considered to be negative, $M=3.07$ and $\mathrm{SD}=0.91$ with about $51.00 \%$ of teachers preferring inclusive schools as opposed to separate schools for students with a disability. A majority of teachers, about $73.83 \%$, thought that inclusive education could have some beneficial outcomes (BOI), $M=4.28$ and $\mathrm{SD}=0.68$. About $61.50 \%$ of teachers, $M=3.68$ and $\mathrm{SD}=0.60$, showed positive attitudes toward integrated classroom management (ICM). Most teachers, about 58.12\%, had negative attitudes about their perceived ability to teach (ATT) students with special needs, $M=2.55$ and $\mathrm{SD}=0.95$. Table 1 presents a summary of the descriptive statistics of the four variables measuring teachers' perceptions of inclusion-benefits of inclusion (BOI), integrated classroom management (ICM), perceived ability to teach (ATT), and perceived concept of inclusion (COI).

The findings suggest that even though teachers were very supportive of the benefits of inclusion, $M=4.28$ and $\mathrm{SD}=0.68$, they would still prefer to have separate schools or classrooms for students with disabilities or special educational needs as shown by their perceptions of the concept of 
TABLE 1: Descriptive statistics of variables in the study $(n=346)$.

\begin{tabular}{|c|c|c|c|c|c|c|}
\hline Variable & Min-max & Mean & SD & Median & Mode & Skewness \\
\hline Benefits of inclusion & $2.25-5.88$ & 4.28 & 0.68 & 4.25 & 4.25 & -0.017 \\
\hline Integrated classroom management & $1.70-5.40$ & 3.68 & 0.60 & 3.70 & 3.70 & -0.022 \\
\hline Perceived ability to teach & $1.00-5.33$ & 2.55 & 0.95 & 2.33 & 2.33 & 0.146 \\
\hline Perceived concept of inclusion & $1.00-5.50$ & 3.07 & 0.91 & 3.00 & 3.25 & 0.039 \\
\hline Total scale & $2.00-4.97$ & 3.40 & 0.54 & 3.35 & 3.08 & 0.288 \\
\hline
\end{tabular}

TABLE 2: Integrated classroom management (ICM) $(N=346)$.

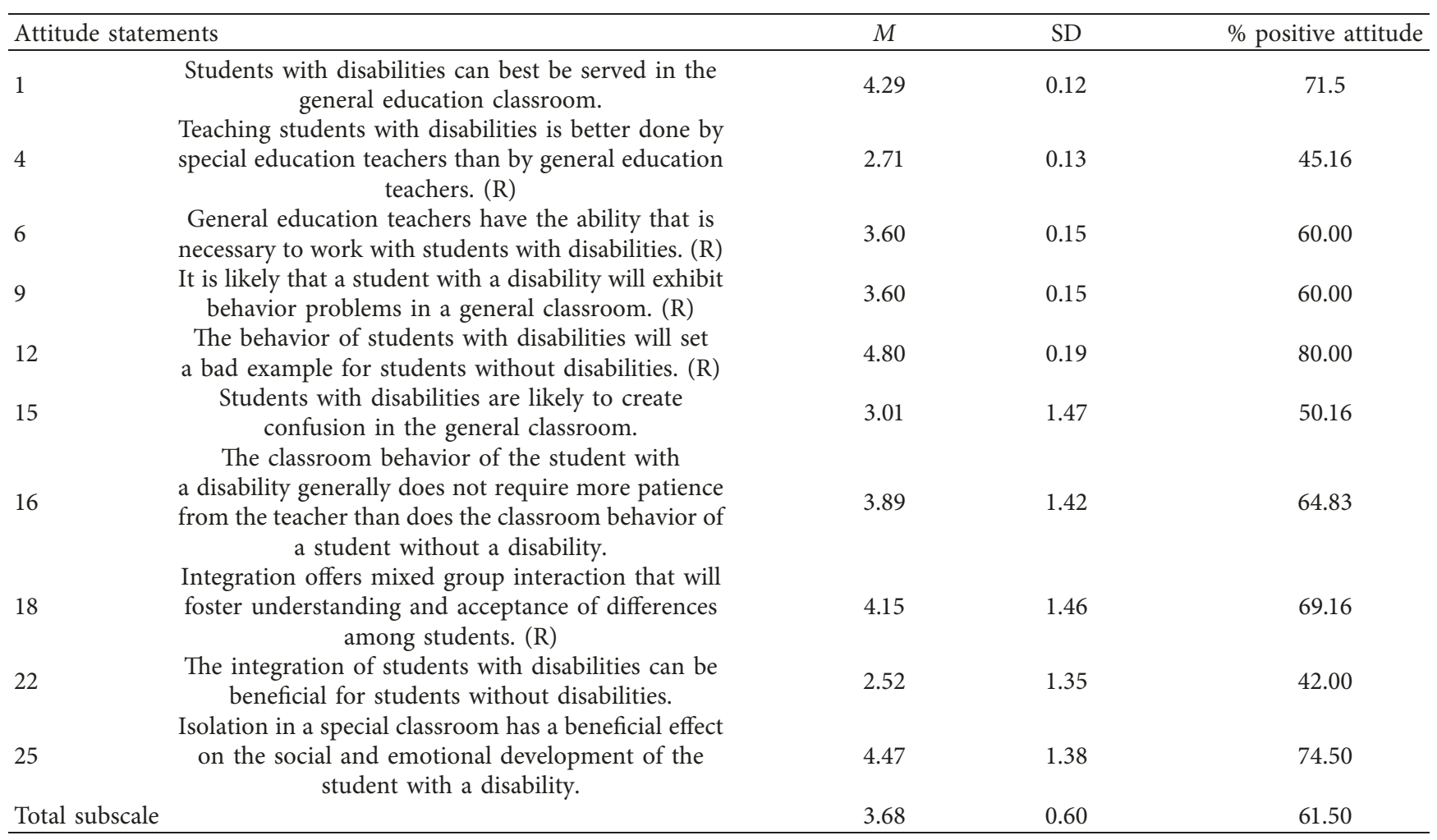

inclusion, $M=3.07$ and $\mathrm{SD}=0.91$. Previous studies have also indicated general education teachers' discomfort with the concept of inclusion [12-14]. On the other hand, Tindall et al. [15] reported a positive change in attitudes and perceptions toward both the idea of inclusion and working with persons with disabilities in Ireland. This finding indicated the possibility for change in attitudes overtime, especially when there is a more concerted effort to promote inclusion through education investment, education training, and sensitization.

Teachers' preference for separate classrooms for children with disabilities is also congruent with the low selfevaluation of their ability to teach students with disabilities. Only $41.88 \%$ of teachers thought that they had the ability to teach students with disabilities, $M=2.55$ and $\mathrm{SD}=0.91$. These findings are congruent with Arrah and Swain [16] who found that general education teachers in Buea, the Southwest Region of Cameroon, needed training to work with special needs students. Other studies have also confirmed that teachers become significantly more accepting of inclusion in schools when they participate in teacher preparation programs and in-service training that combine general and special education curricula [17-19].
The lack of support for the concept of inclusion was affirmed by teacher's belief that the integration of students with disabilities cannot be beneficial for students without disabilities, $M=2.15$ and $\mathrm{SD}=1.35$. Only $42 \%$ of participants thought that integration of students with disabilities can be beneficial for students without disabilities. However, more than an average number of teachers were positive about their abilities to manage integrated classrooms (ICM), $M=3.68$ and $\mathrm{SD}=0.60$ (Table 2). This finding seemed contradictory to teachers' claim that they did not have the ability to teach students with disabilities. However, considering that the participants in the study were teachers in the SEEPD pilot inclusive education program, it is understandable that most of them might have taken part in some of the training workshops on integrated classroom management offered in schools participating in the pilot program $[6,8,20]$. This consideration led to the conclusion that even though teachers recognized the fact that brief training workshops give them an important head start in inclusive education, they still need to receive formal training in inclusive education and special education to cope with the demands of the classroom [8, 17]. 
TABLE 3: Perceptions of personal ability to teach students with disabilities (ATT) $(N=346)$.

\begin{tabular}{|c|c|c|c|c|}
\hline \multicolumn{2}{|c|}{ Perception statements } & \multirow{2}{*}{$\begin{array}{c}M \\
\\
2.17\end{array}$} & \multirow{2}{*}{$\begin{array}{l}\mathrm{SD} \\
1.31\end{array}$} & \multirow{2}{*}{$\begin{array}{c}\text { \% positive attitude } \\
36.16\end{array}$} \\
\hline 2 & $\begin{array}{l}\text { Students with disabilities can best be served in the } \\
\text { general education classroom. (R) }\end{array}$ & & & \\
\hline 10 & $\begin{array}{l}\text { Teaching students with disabilities is better done by } \\
\text { special education teachers than by general education } \\
\text { teachers. (R) }\end{array}$ & 2.94 & 1.50 & 49.00 \\
\hline 19 & $\begin{array}{l}\text { General education teachers have the ability necessary } \\
\text { to work with students with disabilities. }\end{array}$ & 2.43 & 1.37 & 40.5 \\
\hline \multicolumn{2}{|c|}{ Total subscale } & 2.51 & 0.95 & 41.88 \\
\hline
\end{tabular}

In the 1983 law number 83/013, the government of Cameroon legislated support for the education of children with disabilities and their integration in public general education schools. The law also contained provisions for various grants to support special education schools, special pedagogical assistance, training of the specialized staff, and the development of the adapted curricula. The findings of this study and previous studies concur that there have been serious issues with the application of the 1983 law and other recent government executive orders such as the joint circular letter no. 34/06/LC. The executive order (joint circular letter no. 34/06/LC) was signed on 2 August 2006 by the Ministers of Secondary Education and Social Affairs. Its aim was to facilitate the enrolment of children with disabilities or born to poor persons with disabilities, in public secondary schools $[8,16]$. This study reveals that the training of teachers in special education remains a huge hindrance to the implementation of special education laws. Only 64 out of 346 teachers said that they had received training in special education. The support for inclusive education was significantly stronger among teachers who had trained in special education, $M=3.76$ and $\mathrm{SD}=0.52$, as opposed to those who said they had no training, $M=3.68$ and $\mathrm{SD}=0.46$. The results depict that teachers were more likely to be supportive of inclusive education if they had training in special education as opposed to those who did not have any training.

One of the biggest challenges of inclusive education remains the shortage of trained teachers. The local Higher Teachers' Training College located in the SEEPD pilot inclusive education program constituency at Bambili recently initiated a course in IE for guidance counselors and intends to move further to extend this training to classroom teachers [8]. These are timid moves that will not lead to any significant difference in teacher readiness for inclusive classrooms. However, it is a vital initiative that must become more elaborate and consistent. The local training schools and universities need to put in place teacher education programs that have a strong special education component $[17,18]$.

The belief by $58.12 \%$ of teachers that they did not have the ability to teach students with disabilities is not only indicative of teachers' need for training but also an indication that there is still an acute lack of resources to support special education and the teaching of students with disabilities (Table 3 ). The shortages of trained teachers and resources, unfortunately, remain serious, 32 years after the country of Cameroon introduced legislation containing provisions for various grants to support special education schools, special pedagogical assistance, training of the specialized staff, and the development of the adapted curricula [21]. According to the Disability and Rehabilitation Team [5], the acute shortage of resources for special education in Cameroon has not provided a much-needed springboard for the development of inclusive schools. The policy of inclusion can only be effective if regular schools are equipped with facilities, such as self-contained classrooms, resource rooms, trained teachers, and paraprofessionals, needed to provide vital support to students grappling with learning [2, 3]. Indeed, many experts suggest that the success of inclusion depends on the knowledge, instructional skills, and in particular on the attitudes and beliefs of general education teachers toward the integration of students with disabilities $[2,3]$. This study affirms that teachers' ability to teach students (ATT) with disabilities, $M=2.55$ and $\mathrm{SD}=0.95$, is still highly negatively impacted by the lack of knowledge and instructional skills in practice such as differentiated instruction, universal design for learning, and response to intervention, which in turn influence their beliefs and attitudes.

Even though evidence regarding gender as a factor affecting teachers' attitudes toward inclusion is inconsistent, the findings of this study indicate that teachers' gender significantly affected their perceived benefits or outcome of inclusion (BOI) for students $\left(p=0.014\right.$ and $\left.\eta^{2}=0.017\right)$. Any suggestions about why males were more positive about the benefits of inclusion than females would be based on speculation. Findings from many studies [18, 22-24] confirm these inconsistencies, but it is hard to explain why males and females may see things differently on this subject. A historical and sociocultural analysis of the context may give clues that explain why female teachers were less positive about the benefits of inclusion than their male colleagues. While the results of some studies reveal that male teachers had more positive attitudes than female teachers, results of other studies indicate that female teachers had more positive attitudes toward inclusion [22, 25-27].

Regarding age, older teachers tended to be more supportive of inclusive education than younger ones. This finding revealed that older teachers in general education schools engaged in the practice of inclusive education were not resistant to change nor did they have the tendency to want to preserve the status quo, as suggested by Clarke [28]. The more positive attitudes shown by older teachers could be indicative of continuous exposure to the practice of special education, and ongoing professional learning opportunities had given them more ability to accommodate students with 
a disability [29]. This positive attitude is also an indication of the importance of continual in-service training for teachers on the management of inclusive classrooms. These findings do not concur with the conclusions of researchers who said that age did not influence teachers' attitudes toward inclusion [30]. Similarly, they do not concur with earlier findings that younger persons indicated more positive views toward the inclusion of students with a disability in the general education classrooms [31].

The higher the level of education, the more likely the teachers were going to be supportive of inclusive education. This is congruent with most literature on teachers' attitudes toward inclusive education. Teachers with Master's or Doctoral degrees had significantly more positive attitudes than those with Bachelor's degrees when teachers' perceived ability to teach children with disabilities and their perceived concept of inclusion were examined. Dupoux et al. [32] found that teachers with a Master's degree had a more positive attitude toward inclusive education $(M=3.45$ and $\mathrm{SD}=0.61)$ than those who had less than a Master's Degree $(M=3.10$ and $\mathrm{SD}=0.49)$ on the attitudes of elementary and secondary school teachers. Moberg and Savolainen [33] conclude that teachers with higher qualifications have positive attitudes toward inclusion than teachers with lower qualifications. These conclusions indicated the need for educational authorities in Cameroon to provide incentives for teachers to pursue graduate specializations in teacher education. The deduction here is that the more the teachers are educated, the more likely they will be exposed to training likely to improve their ability to teach students with special needs.

In a context like the one studied, where teachers agree that they need more training to have the ability to teach students with disabilities, it means that giving teachers the opportunity to get more training, do graduate programs, or take graduate level courses related to inclusive education would likely be beneficial. Also, supportive attitudes by teachers who said they had training in special education as opposed to their counterparts with no training indicated that the training of more teachers in special education can make a difference in the practice of inclusive education. It is the duty of inclusive schools such as the SEEPD program schools and educational authorities to recognize and respond to the diverse needs of students, ensure the accommodation of both different styles and rates of learning, and provide quality education to all through appropriate curricula, organizational arrangements, teaching strategies, resource use, and partnerships with their communities. These goals are accomplished by making sure that teachers receive quality training and are provided with the resources needed to work in inclusive classrooms [34].

Teachers should not find themselves in a situation which demands that they look for information and resources needed for routine classroom activities [34, 36]. Rather, teachers should be provided all the support needed for them to embrace new inclusive education initiatives such as the SEEPD pilot program and other similar nascent initiatives in Cameroon. A review of teachers' needs is always very crucial because teachers' complaints about resources need "clarity about the nature of the resources required, and indeed why they are needed at all" [36]. Boyle et al. [37] had also argued that putting the wrong resources into the inclusive education environment without a clear and specific action plan could worsen teachers' output instead of improving it. In the context of Cameroon, it is necessary to be certain about what the exact needs of teachers are as well as the expectations regarding outcomes.

Several studies investigating teachers' attitudes toward inclusive education practices have concluded that teachers with more years of experience had a more negative attitude toward inclusion than teachers with fewer years of teaching experience $[23,25,33,38]$. The study did not concur with these studies entirely. Rather, attitudes toward inclusive education by teaching experience indicated that teachers' support grew in the early years of their career (6 years to about 25 years) but steadily falls after 30 years of teaching, $F$ $(6,340)=4.08, p=0.001$, and $\eta^{2}=0.067$. Teachers with 31 years or more of teaching experience certainly need more professional support and incentives, if these results are an indication that teachers' motivation to teach inclusive classrooms is on the decline after 30 years of teaching. Studies on inclusive education and special education in Cameroon have consistently indicated inadequate technical and material support for teachers [7, 8, 39 40]. The persistence of this lack of resources can lead to frustration among teachers, which might explain why these findings indicate that the more experienced the teachers became, the more likely they were going to be unsupportive of inclusive classrooms.

4.1.1. The Benefits of Integration (BOI). Teachers' attitudes regarding the benefits derived from the practice of inclusive education were measured using items $3,7,11,14,17,20,21$, and 24 . Table 4 shows that the mean score for teachers' perceived benefits of inclusion was 4.28 , and the standard deviation was 0.68 . About $73.83 \%$ of teachers (respondents) reported positive attitudes about the benefits of inclusion or integration of special needs students in the general education classroom.

4.1.2. Integrated Classroom Management (ICM). Teachers' attitudes toward the concept of integrated classroom management were measured using items $1,4,6,9,12,15,16$, 18,22 , and 25 . The attitudes mean score for this variable was 3.68 , and the standard deviation was 0.60 . Table 2 shows that $61.50 \%$ of teachers' attitudes toward integrated classroom management were positive. However, only $54.84 \%$ of participants thought that teaching students with disabilities is better done by special education teachers than by general education teachers.

4.1.3. Perceptions of Personal Ability to Teach Students with Disabilities (ATT). Teachers' self-perception of their ability to teach students with special needs were considered negative; the mean score was 2.51, and the standard deviation was 0.95 (Table 3). Items 2, 10, and 19 measured teachers' perceptions of their capacity to teach students with special needs. Only $41.88 \%$ of teachers showed positive attitudes 
TABLe 4: Benefit/outcomes of Integration (BOI) $(N=346)$.

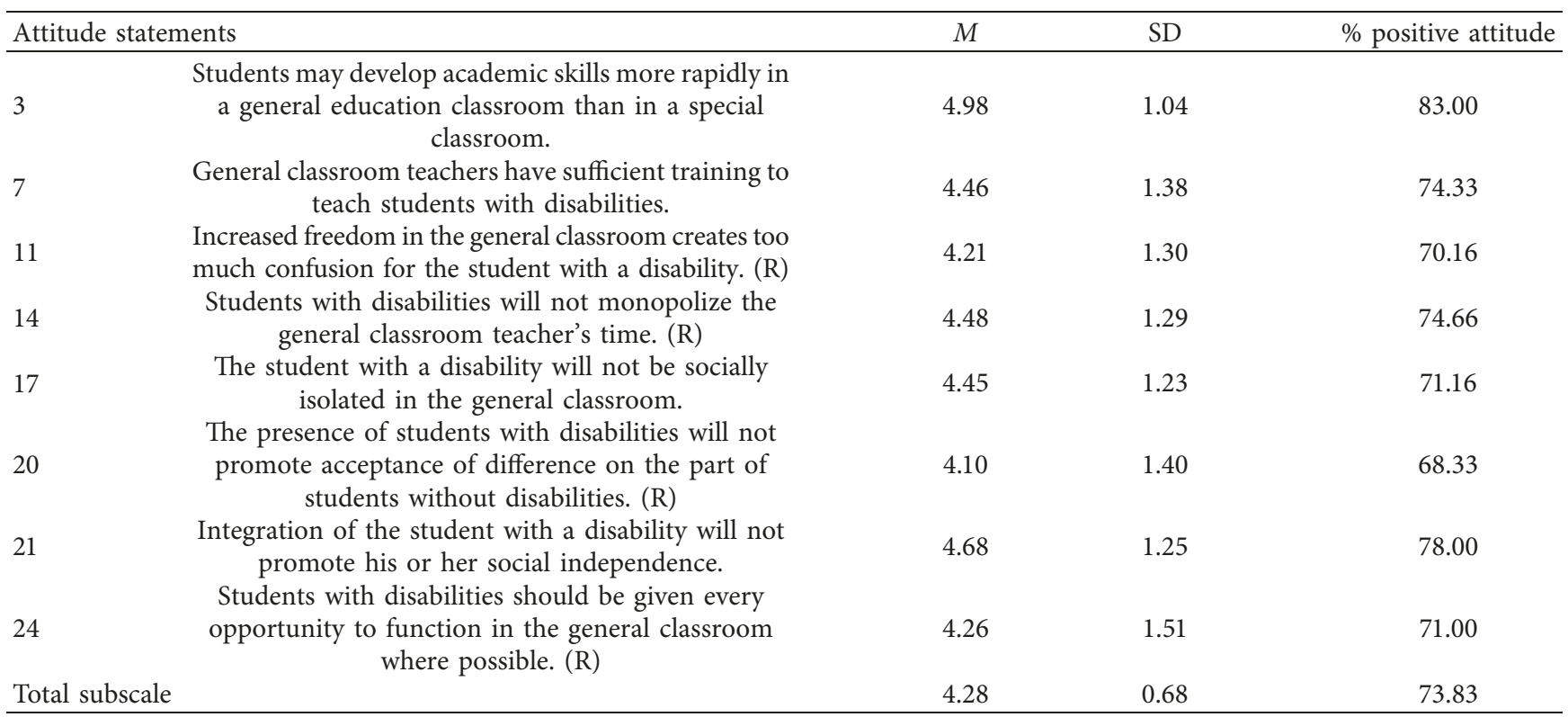

Note. $\mathrm{R}=$ reversed items.

Table 5: Perceptions of concept of inclusive education (COI) $(N=346)$.

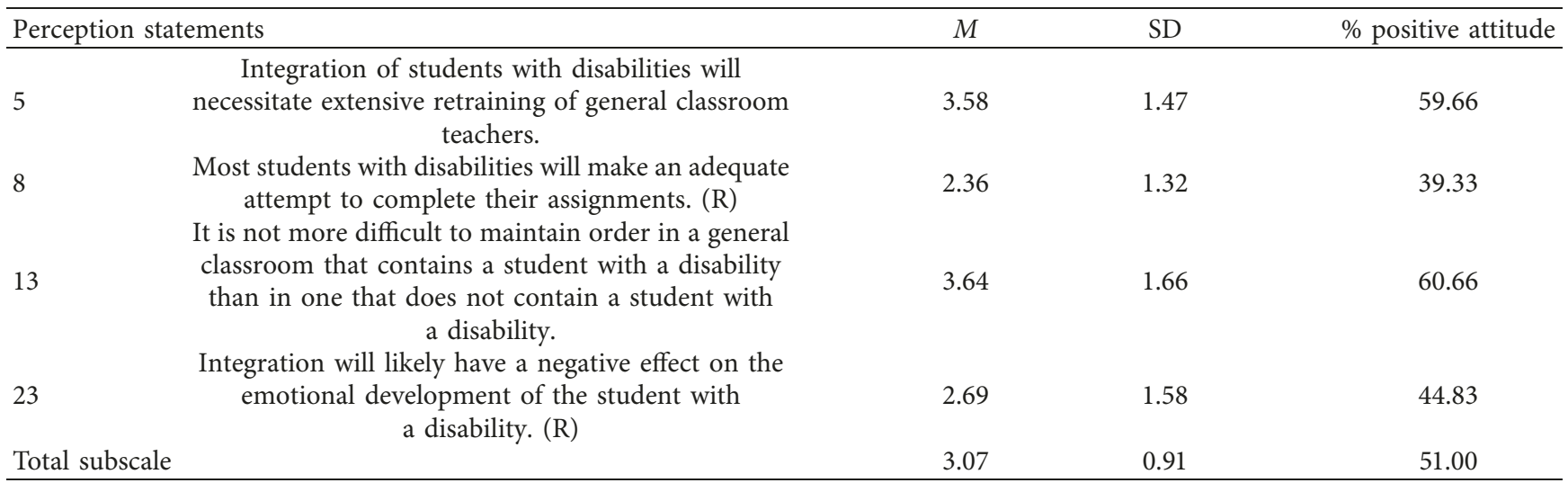

regarding their personal abilities to teach students with disabilities, $M=2.51$ and $\mathrm{SD}=41.88$ (Table 3).

4.1.4. Perceived Concept of Inclusion (COI). Teachers attitudes toward special education compared to inclusive education were negative, the mean score was 3.07 , and the standard deviation was 0.91 (Table 5). These perceptions, based on teachers' responses to questions 5, 8, 13, and 23, indicated negative attitudes by the teachers' idea of inclusion. About half the number of participants (51.00\%) said they believed that inclusion would not be beneficial to both students with disabilities and those within the general education system, $M=3.07$ and $\mathrm{SD}=0.19$ (Table 5).

4.2. Research Question 2. The results indicated that participants' perceptions of inclusive education were significantly different by their gender, age, the level of education, teaching experience, experience teaching in the inclusive classroom, and training in teaching students with special education needs.

4.2.1. Gender. MANOVA was significant by gender regarding teachers' perception of the benefits of inclusion (BOI) and integrated classroom management (ICM): Wilks' lambda $=0.969, F(4,341)=2.709$, and $p=0.030$. Teachers' genders significantly affected their perceived benefits of inclusion (BOI) $(p=0.014$ and partial eta squared $=0.017)$ and perceived integrated classroom management (ICM) $(p=0.038$ and partial eta squared $=0.012)$. Male participants were more positive about the BOI and ICM than their female counterparts. Avramidis and Norwich [25] explained in their study that while the results of some studies reveal that male teachers have more positive attitudes than female teachers, results of other studies indicate that female teachers have more positive attitudes toward inclusion. The findings of the study by Jobe et al. [22] concur with the results of this dissertation but do not concur with the study by Leyser and 
Kirk [23], and Boyle et al. [18] found that female teachers had more positive attitudes toward inclusion than male teachers. On the other hand, Avramidis et al. [30] found that gender was not significantly related to teachers' attitudes toward inclusion.

4.2.2. Age. Overall attitudes toward inclusion indicated that older teachers tended to be accepting of inclusive education than younger ones. Older teachers showed more favorable attitudes toward inclusive education than younger teachers-the older a teacher, the more likely he or she was going to be supportive of inclusive education. Teachers 40 years old and above were more supportive of inclusive education than their younger colleagues, $F(5,340)=4.62, p=0.00$, and $\eta^{2}$ (effect size $)=0.064$. According to the study conducted by Burge et al. [31], younger teachers showed more positive attitudes toward including students with disabilities in the general education classrooms. According to the study conducted by Burge et al. [31], younger teachers showed more positive attitudes toward including students with disabilities in the general education classrooms. Nevertheless, some studies have revealed that age does not influence teachers' attitudes toward including students with special education needs in their classrooms [30].

4.2.3. Level of Education. Attitudes toward inclusion on the basis of the level of education indicate that the more educated teachers tended to be more supportive of inclusive education than lesser educated ones. The higher the level of education, the more likely the teachers were going to be supportive of inclusive education, $F(2,340)=7.95, p=0.00$, and $\eta^{2}$ (effect size) $=0.044$. These results are conversant with those of Dupoux et al. [32] and Moberg and Savolainen [33] who concluded that teachers with higher qualifications had positive perceptions than those with lower qualifications.

4.2.4. Teaching Experience. There were significant differences in teachers perceptions on the basis of teaching experience in the following variables: BOI, $F(6,34)=3.90$, $p<0.05$; ATT, $F(6,84)=2.56, p<0.05$; and COI, $F(6,34)=$ $3.94, p<0.01$. The results indicated that the three dependent variables were significantly affected by teaching experience because the effect size for these variables is considered to be large. Overall attitudes toward inclusive education on the basis of teaching experience indicated that teachers' support grew in the early years of their career (6 years to about 25 years), but the support steadily falls after 30 years of teaching, $F(6,340)=4.08, p=0.001$, and $\eta^{2}$ $($ effect size $)=0.067$.

4.2.5. Experience Teaching in the Inclusive Classroom. Teachers' teaching experience in special education classrooms has significantly affected their perceived ability to teach children with disabilities: ATT, $F(1,34)=5.27, p<0.05$ and COI, $F$ $(1,34)=10.99, p<0.05$. Neither teachers' perceived BOI nor their ICM were statistically significant: BOI, $F(1,34)=2.14$, $p>0.05$ and ICM, $F(1,34)=2.26, p>0.05$. Teachers who said that they had some experience teaching special needs students in an inclusive classroom $(M=3.49$ and $\mathrm{SD}=0.54)$ tended to be more supportive of inclusive education than those who said they had no experience $(M=3.29$ and $\mathrm{SD}=0.53), F(1,34)=11.99, p=0.003$, and $\eta^{2}($ effect size $)=$ 0.025 . Results of studies carried out by Avramidis and Norwich [25], and Taylor et al. [38] were contrary to those of this study in that teachers with more years of teaching experience were less supportive of inclusive education than those with fewer years.

4.2.6. Training in Special Education. Teachers' attitudes toward inclusive education affected their perceived concept of inclusion (COI), $F(1,34)=5.33$ and $p<0.05$. The overall mean score for teachers who said they had never received any training in special education, $M=3.68$ and $\mathrm{SD}=0.46$, was significantly lower than the mean score for those who stated that they had received some form of training in special education, $M=3.79$ and $\mathrm{SD}=0.52$. This means that teachers were more likely to be supportive of inclusive education if they had training in special education as opposed to those who did not have any training. O'Toole and Burke [41] in their study of preservice teacher attitudes towards inclusive education reveal that teachers were positive about inclusion accounted for by their higher level of personal efficacy and lower levels of concern.

\section{Implications for Instructional Leadership}

The findings of this study underscore the importance of instructional leadership to the implementation of any educational program that needs substantial investments in both human and material resources. Inadequacies in teachers' training on special education and inclusive classroom management could also be explained by serious weaknesses in instructional leadership in Cameroon. Cotton [42] argues that effective instructional leaders are intensely involved in curricular and instructional issues that directly affect students' achievement, especially the achievement of students with disabilities. This important role is not the sole responsibility of school principals. It extends beyond the principal to include other educational leaders-central office personnel (superintendent and curriculum coordinators), principals and assistant principals, and department heads [43-45]. In Cameroon, with a very centralized school system, the role of instructional leadership lies in the hands of the Ministers of Education, the Regional Delegates, the Divisional Delegates (superintendents), School Principals and Vice Principals, and Department Heads. This system encourages an extreme form of bureaucracy that does not only make instructional leadership complicated but also riddled with waste and mismanagement. As a result, funding needed to implement important policy, finance important services, invest in teacher training, and buy essential equipment for inclusive classrooms is rarely available. The findings of this study confirm this crude reality, which makes instructional leadership very ineffective. 
For instructional leadership geared at revamping the implementation of inclusive education to be effective, educational leaders at the national, regional, and district levels have to take charge of teachers' concerns identified in this study. Based on the findings of the study as reflected by teachers' perspectives on the practice of inclusive education in the seven selected secondary schools engaged in the SEEPD pilot inclusive education program, recommendations to revamp instructional leadership are grouped into eight main areas of concern. These include (a) introduction of special education courses in teacher-training colleges, (b) ongoing professional development in inclusive education, (c) creation of special education programs in public and private universities, (d) adaptive curriculum development and dissemination, (e) training and recruitment of professionals and paraprofessionals, and (f) prioritizing new funding sources for inclusive education. These areas of concern can be taken care of by three levels of instructional leadership in the Cameroonian education system, namely, (a) national level (Ministries of Basic and Secondary Education), (b) regional level (regional and district (division) officials), and (c) intuitional level (principal, vice principal, and head of department).

\subsection{Introduction of Special Education Courses in Teacher Training}

5.1.1. Colleges and Universities. This study revealed that the participants who are for the most part graduates from the government-funded teacher-training colleges were more supportive of inclusive education if they had training in special education $(M=3.76$ and $\mathrm{SD}=0.52)$ as opposed to those who did not have any training $(M=3.68$ and $\mathrm{SD}=0.46)$. Out of a total of 346 teachers who participated in this study, $18.5 \%$ of teachers said that they had received some form of training in special education while $81.5 \%$ said that they never had training in special education. Teachers' training in special education or lack thereof also influenced their perceived concept of inclusion. They tended to be more supportive of the concept of inclusion as opposed to separate schools for students with disabilities when they had received some form of training in special education $(M=3.30$ and $\mathrm{SD}=0.88)$. Teachers with no training were significantly less supportive of the concept of inclusion $(M=3.0$ and $\mathrm{SD}=0.91$ ). As a result, the government should ensure the introduction of special education courses in the three higher teacher-training colleges as well as in the universities of Cameroon The trained special education specialists can lead the effort of inclusion by providing coaching and counsel to their general education colleagues managing inclusive classrooms. Friend and Bursuck [46] conclude that the ability of general education teachers to accommodate students with special education needs is contingent on guidance from resource teachers or special education teachers who coordinate student services and IEPs (Individualized Education Programs) for each student with special education needs.

When more than $80 \%$ of teachers involved in a pilot inclusive education program say they have no training in special education, it is clear that something needs to be done. These conclusions fall in line with the findings of Tohnain et al. [20] who identify the absence of courses and programs for the education of people with disabilities in teachertraining colleges in Cameroon as a major drawback to the implementation of inclusive practices in regular schools. With no programs for special education teachers in government colleges and universities, it is impossible for government to lead in the promotion of special education and inclusion in schools. In a country where $90 \%$ of schools and colleges are owned and run by the government, it is logical for it to ensure that teachers and paraprofessional receive the training required to lead in their effort to promote inclusive schools.

The slow pace of the development of inclusive education schools in the country was not unexpected because the 1984 legislation instituting government aid to special education and the development of inclusive education also stated that the financing of inclusive classrooms will depend on the means available to the authorities [21]. This study indicates from its findings that for special education and inclusive education to work properly in Cameroonian schools, authorities have to prioritize its funding, including the unconditional provision of funds for teacher education, the creation of special education programs in colleges and universities, and the development of self-contained classrooms and instructional tools and resources.

5.2. Training and Recruitment of Professionals and Paraprofessionals. The successful implementation of any inclusive education initiative requires the efforts of trained special education teachers and paraprofessionals. A good diagnosis, categorization, and accommodation of special needs students will only be possible when the Cameroonian education system has a reasonable number of trained special education professionals, including teachers, paraprofessionals, and related service providers. The results of this study indicate the shortage of special education professionals and by implication the absence of paraprofessionals. In a context where more than $80 \%$ of teachers have either had no experience in teaching students with disabilities or received any form of training on inclusive education, it is evident that there is a huge need to train not only special education professionals but also paraprofessionals. This is responsibility that educational leaders at the national level have led on by hiring and training not only general education teachers as in the current practice but also hiring and training special education teachers and paraprofessionals.

\subsection{Breaking Cultural Barriers to Inclusive Education.} Literature on special education and the treatment persons with disabilities in Cameroon indicate that the negative attitudes toward the concept of education could also be attributed to factors such as cultures, norms, and traditions of Cameroon. The Cameroonian cultures, for the most part, see the bringing up and education of children with disabilities as the responsibility of the parent. This belief explains why the local cultures in Cameroon are both helpful and harmful to the condition of persons with disabilities. The 
strong family support system within the communities compensates, to some extent, for the acute shortage of special education facilities. Tukov [39] asserts that children with hearing impairments, visual impairments, autism, mental retardation, and physical or health disabilities receive invaluable support from parents and family members. There is always someone home to provide for their basic needs. Notwithstanding, it is important to help teachers move away from this mindset by helping them receive the right training and accept their role in the education of children with special needs, especially in inclusive environments. This can be done by developing special education programs with courses designed to improve sensitivities and increase tolerance and acceptance for persons with disabilities.

5.4. Ongoing Professional Development. The significant difference in the support of inclusive classrooms between teachers who had had some prior experience teaching students with disabilities $(M=3.49$ and $\mathrm{SD}=0.54)$ and those who had no experience $(M=3.29$ and $\mathrm{SD}=0.53)$ shows a need for ongoing professional training. Effective instructional leadership with regard to ongoing professional development can be taken care of at the regional, district, and school levels. The superintendents and school principals can ensure that in-service training in inclusive education receives consistent funding from the budget they receive from government: the Ministry of Basic Education and the Ministry of Secondary Education. It is true that funds are considerably slashed by the time they reach the schools, but principals can make a difference by properly managing the insufficient funds they receive from government. According to Inclusive Schools Network [47], the most critical role in successful inclusive schools is the role of the principal. They purport that the school principal's active participation is the single most important predictor of success in implementing change, improving services, or setting a new course. The school principal is central to facilitating systemic change and leading faculty to adopt new attitudes and new practices [42]. It is the most direct instructional leadership likely to make a difference in the quality of teaching and learning of all children enrolled in inclusive schools.

There is a strong need to institute and strengthen the special education component in professional development programs in schools. Even when teachers do not receive formal training in schools on how to manage inclusive classrooms, they can still become productive if given the chance to improve their knowledge and skills through short in-service training programs such as seminars and training workshops. The SEEPD program leaders seem to understand the need for professional development, which explains why they have come up with a plan to construct the first resource center in the Government Bilingual High School in Bamenda. This center will serve as a location for seminars and workshops and provide a library, ICT, Braille services, books, and equipment related to the education of students with disabilities [48]. Also, National and Regional Boards education could also institute required courses in special education as part of a teacher's preservice educational requirements. These measures will provide teachers the basics as well as upgrade the skills of experienced teachers on contemporary issues regarding inclusive education.

5.5. Adaptive Curriculum Development and Dissemination. For successful inclusive education to take place, teachers need to tailor the curriculum to suit the needs of all students. To achieve effective inclusion, it begins with good diagnosis and categorization of students with special education needs. Without clear categorization, the development and dissemination of curricula adapted to the needs of the students with disabilities become an uphill task. Findings of this study indicate an acute shortage of trained professionals who can ensure proper identification of disabilities as well as the development of curricula that can accommodate the students with various disabilities in general education classrooms.

Literature indicates that this can be done through the Universal Design for Learning strategy. It is a theoretical framework that guides the development of curricula that are flexible and supportive of students with special education needs [49-51]. The concept calls for the design of structures that anticipate the needs of individuals with disabilities and the accommodation of these needs from the onset [40]. Instruction is led at this level by department heads under the tutelage of principals and vice principals. The curriculum should be innately flexible, enriched with multiple media, so that the alternatives can be assessed whenever necessary. In order to ensure a successful design for structures that take adequate care of students with special needs of different categories, it is important to begin by creating a special workforce to analyze the current curriculum, in addition to the one that determines how to test and evaluate students with specific needs.

5.6. Prioritizing New Funding Sources for Inclusive Education. Training of special education and inclusive education professionals in Cameroon requires much investment by government and other education stakeholders such as churches and local organizations. A major reason for the shortage of trained professionals could be the lack of funding for teacher-training programs, resources, and pilot inclusive education programs such as the SEEPD program. Mbibeh [8] points out that parents, teachers, and administrators are of the opinion that "low budgetary allocations are impediments to the implementation of IE" (p. 65).

\section{Recommendations to the SEEPD Program Managers}

The SEEPD program is not a sufficiently funded program. As a result, the program goals and capacity are limited by its means. This explains why the program covers only select schools in one of the ten regions of Cameroon. Based on the findings of this study, the SEEPD program leaders can do the following things to improve its implementation and scope: 
(1) Develop an intensive in-service training program for teachers in special education, in general, and inclusive education, in particular. Such programs should be continuous, and professionals should be invited to provide much-needed expertise in inclusive classroom teaching strategies for effective instruction such as Differentiated Instruction, Universal Design for Learning, and Responses to Intervention.

(2) Seek funding from diverse sources to ensure that indispensable resources such as assistive technologies are made available to students. Considering the financial limitations faced by the program, it will only be able to acquire useful assistive resources through partnerships. Physically challenged students need mobility aids, such as wheelchairs, scooters, walkers, canes, crutches, prosthetic devices, and orthotic devices, to enhance their mobility. Other assistive devices that could make a difference for the program participants are audio players, timers, reading guides, FM listening systems, calculators, writing supports, and graphic organizers.

(3) Partner with foreign schools for teachers and students to have access to basic didactic resources such as textbooks, student workbooks, worksheets, large print texts, Braille texts, videos, software, and Internet resources.

\section{Recommendations for Future Research}

The findings of the study show the need for further research in several inclusive education related areas, including the following:

(1) Studies that follow-up on the results of this study. This study investigated the attitudes of secondary school teachers in a pilot inclusive education program. This pilot program covers both primary $(\mathrm{k} 1-5)$ and secondary (grades 6-12) schools. It will be logical to suggest for two follow-up studies. The first of the two studies would investigate primary school teachers' attitudes in the same pilot inclusive education program.

(2) A second study could be done to compare primary school teachers' attitudes toward inclusive education with those of the secondary school teachers. Such a study will not only determine if the ages of students with disabilities influence how teachers perceive their ability to learn in an inclusive environment, but also if teachers' levels of education influence their perceptions since primary school teachers in the country are less educated-most of them are not college graduates.

(3) The impact of the availability of resources. Teachers' abilities to teach students with special needs are largely affected by the availability of resources. Further research can be done to find out teachers' beliefs about the availability of resources and the usefulness of such remedies. Their opinions about the types of support needed and from whom they expect the support would constitute important informative data that could be used by educational stakeholders.

(4) The influence of customs, traditions, and beliefs on attitudes teachers have toward students with disabilities and their inclusion in general education classrooms is still strong among Cameroonian K-12 teachers. An indication of this influence of this finding could be seen in the current study where $82.95 \%$ of teachers think that most students with disabilities will not be able to make an adequate attempt to complete their assignments. The perception certainly influences this mindset that persons with disabilities are "handicapped" individuals. A sociocultural investigation of the impact of culture on Cameroonian teachers' attitudes toward inclusive education in the 21 st century can reveal salient barriers to inclusion that would otherwise be neglected.

(5) A follow-up study that investigates whether or not teachers' levels of consent for inclusive education vary by the type of disabilities. This variation is likely an area of interest because the challenges of integration of students with physical disabilities would differ from those of students with emotional and behavioral disorders.

\section{Summary and Conclusion}

This study reveals that there is still a learning by teachers in Cameroon toward separate special education schools for children with disabilities. Another investigation on whether or not such a preference is dependent on students' levels of disability-mild, moderate, or severe-could be more revealing. SEEPD teachers' perceptions of the concept of inclusion (or special versus integrated general education) indicate an overall negative attitude toward inclusive classrooms [53]. With $58 \%$ of teachers thinking that the integration of students with disabilities cannot be beneficial for students without disabilities, it is clear that for inclusive education to be embraced, a concerted effort will be needed from all education stakeholders in Cameroon (Table 2). It is even more of a concern when $60.67 \%$ of teachers think that most students with disabilities will not make an adequate attempt to complete their assignments in an inclusive learning environment (Table 5). The findings of this study point to the reality that the acceptance and growth in the practice of inclusive education in Cameroon remain challenging. The time it eventually takes to reach the ultimate goal, which is the total acceptance and effective implementation of existing inclusive education policies, will depend to a significant extent on the contribution of national educational stakeholders, including government, churches, private individuals, educational leaders, and teachers.

This study was conducted in general education secondary schools actively engaged in a pilot effort to introduce inclusive classroom practices in select bilingual secondary schools [53]. It is not certain what the level of acceptance of 
integrating students with disabilities into the general education classroom would be if the study were carried out in schools not actively involved in the inclusive education initiative. Nonetheless, what stands out about the findings of this study is that most teachers showed negative attitudes about the success or outcome of inclusive education and indicated that the training they received in special education and inclusive education was not enough to ensure a successful integration of students with disabilities into the general education classrooms. These findings support not only the rationale but also the urgent need for investment by all Cameroonian education stakeholders, especially the leading sponsor of education, the government, in the training of special education professionals in the country. These revelations also constitute a call for needed action from instructional leaders and higher education leaders who can make a difference by promoting professional development through seminars and workshops as well as creating targeted special training education programs in the various institutions of higher learning in the country.

\section{Conflicts of Interest}

The authors declare that they have no conflicts of interest.

\section{References}

[1] UNESCO, The Salamanca Statement and Framework for Action on Special Needs Education: Access and Quality, United Nations Ministry of Educational, Scientific and Education and Science Cultural Organization, Salamanca, Spain, 1994, http:// www.unesco.org/education/pdf/SALAMA_E.PDF.

[2] B. G. Cook, "A comparison of teachers' attitudes toward their included students with mild and severe disabilities," Journal of Special Education, vol. 34, no. 4, pp. 203-213, 2001.

[3] M. Friend and W. D. Bursuck, Including Students with Special Needs: A Practical Guide for Classroom Teachers, PrenticeHall, New Jersey, NY, USA, 2006.

[4] D. P. Rivera and D. D. Smith, Teaching Students with Learning and Behavior Disabilities, Allyn \& Bacon, Boston, MA, USA, 3rd edition, 1997.

[5] Disability and Rehabilitation Team, The UN Standard Rules on the Equalization of Opportunities for Persons with Disabilities, Regional Report AFRO, World Health Organization, Geneva, Switzerland, 2002.

[6] SEEPD, Local and International Instruments Backing Inclusive Education Practice in Cameroon, Wiley, Bamenda, Cameroon, 2011.

[7] N. P. Ebontane, "Handicapism: the case of the hearing impaired in inclusive education in Cameroon: implications for planning and policy," Nigerian Journal of Guidance and Counseling, vol. 15, no. 1, pp. 1-10, 2010.

[8] L. Mbibeh, "Implementing inclusive education in Cameroon: evidence from the Cameroon Baptist Convention Health Board," International Journal of Education, vol. 5, no. 1, pp. 52-68, 2013.

[9] MINEDUC, Report on the Distribution of Licensed Secondary School Teachers by Region, Ministère de l'Education Nationale (MINEDUC), Yaounde, Cameroon, 2005.

[10] R. F. Antonak and B. Larrivee, "Psychometric analysis and revision of the opinions relative to mainstreaming scale," Exceptional Children, vol. 62, no. 2, pp. 139-147, 1995.
[11] B. Larrivee and L. Cook, "Mainstreaming: a study of the variables affecting teacher attitude," Journal of Special Education, vol. 13, no. 3, pp. 315-324, 1979.

[12] S. Chhabra, R. Srivastava, and I. Srivastava, "Inclusive education in Botswana: the perceptions of school teachers," Journal of Disability Policy Studies, vol. 20, no. 4, pp. 219-228, 2010.

[13] T. Thaver and L. Lim, "Attitudes of pre-service mainstream teachers in Singapore towards people with disabilities and inclusive education," International Journal of Inclusive Education, vol. 18, no. 10, pp. 1038-1052, 2014.

[14] L. Bailey, A. Nomanbhoy, and T. Tubpun, "Inclusive education: teacher perspectives from Malaysia," International Journal of Inclusive Education, vol. 19, no. 5, pp. 547-559, 2015.

[15] D. Tindall, W. MacDonald, E. Carroll, and B. Moody, "Preservice teachers' attitudes toward children with disabilities: an Irish perspective," European Physical Education Review, vol. 21, no. 2, pp. 206-221, 2015.

[16] R. O. Arrah and K. D. Swain, "Teachers' perceptions of students with special education needs in Cameroonian secondary schools," International Journal of Special Education, vol. 29 , no. 3, 2014.

[17] K. Ji-Ryun, "Influence of teacher preparation programmes on preservice teachers' attitudes toward inclusion," International Journal of Inclusive Education, vol. 15, no. 3, pp. 355-377, 2011.

[18] C. Boyle, K. Topping, and D. Jindal-Snape, "Teachers' attitudes towards inclusion in high schools," Teachers and Teaching, vol. 19, no. 5, pp. 527-542, 2013.

[19] P. Engelbrecht, M. Nel, N. Norma, and T. Dan, "Enacting understanding of inclusion in complex contexts: classroom practices of South African teachers," South African Journal of Education, vol. 35, no. 3, pp. 1-10, 2015.

[20] L. N. Tohnain, G. E. Fonkeng, and N. Ngueffo, "Educational Research Network for West and Central Africa (ERNWACA) report on children living with disabilities and education in Cameroon: challenges and Perspectives," 2008, http://www.rocare. org/grants/2008/Children\%20living\%20with\%20disabilities\% 20 and\%20education\%20in\%20Cameroon.pdf.

[21] P. Biya, Loi n 83-013 du Juillet 1983 Relative à la Protection des Personnes Handicapées, Yaounde, Cameroon, 1984, http://www. afub-uafa.org/sites/default/files/Cameroon\%20Report.pdf.

[22] D. Jobe, J. O. Rust, and J. Brissie, “Teachers' attitudes toward inclusion of students with disabilities into regular classrooms," Education, vol. 117, no. 1, pp. 148-153, 1996.

[23] Y. Leyser and R. Kirk, "Evaluating inclusion: an examination of parent views and factors influencing their perspectives," International Journal of Disability Development and Education, vol. 51, no. 3, pp. 271-285, 2004.

[24] S. Stubbs, "Attitudes of general education teachers in grades one through six toward inclusion in new providence, Bahamas," Ph.D. thesis, ProQuest Dissertations and Theses database (UMI No. 3339234), George Washington University, Washington, DC, USA, 2009.

[25] E. Avramidis and B. Norwich, "Mainstream teachers' attitudes towards inclusion/integration: a review of the literature," European Journal of Special Needs Education, vol. 17, no. 2, pp. 129-147, 2002.

[26] A. Carroll, C. Forlin, and A. Jobling, "The impact of teacher training in special education on the attitudes of Australian pre-service general educators towards people with disabilities," Teacher Education Quarterly, vol. 30, pp. 65-79, 2003. 
[27] J. Ellins and J. Porter, "Departmental differences in attitudes to special educational needs in the secondary school," British Journal of Special Education, vol. 32, no. 4, pp. 188-195, 2005.

[28] J. S. Clarke, Personal and Organizational Structure Correlates of Receptivity and Resistance to Change and Effectiveness in Institutions of Higher Education, Louisiana State University, Baton Rouge, LA, USA, 1997.

[29] Y. Hwang and D. Evans, "Attitudes towards inclusion: gaps between belief and practice," International Journal of Special Education, vol. 26, no. 1, pp. 136-146, 2011.

[30] E. Avramidis, P. Bayliss, and R. Burden, "A survey into mainstream teachers' attitudes towards the inclusion of children with special educational needs in the ordinary school in one local educational authority," Educational Psychology, vol. 20, no. 2, pp. 193-213, 2000.

[31] P. Burge, H. Ouellette-Kuntz, and N. Hutchinson, "A quarter century of inclusive education for children with intellectual disabilities in Ontario: public perceptions," Canadian Journal of Educational Administration and Policy, vol. 87, pp. 1-22, 2008.

[32] E. Dupoux, H. Hammond, L. Ingalls, and C. Wolman, "Teachers' attitudes toward students with disabilities in Haiti," International Journal of Special Education, vol. 21, no. 134, pp. 1-14, 2006.

[33] S. Moberg and H. Savolainen, "Struggling for inclusive education in the north and the south: educators' perceptions on inclusive education in Finland and Zambia," International Journal of Rehabilitation Research, vol. 26, pp. 21-31, 2003.

[34] U.S. Department of Education, The Individuals with Disabilities Education Act of Amendments of 1997. Final Regulations, U.S. Department of Education, Washington, DC, USA, 1999, https://www2.ed.gov/pubs/AnnualPlan2001/ index.html.

[35] R. Gersten and J. Woodward, "Rethinking the regular education initiative: focus on the classroom teacher," Remedial and Special Education, vol. 11, no. 3, pp. 7-16, 1990.

[36] F. Lauchlan and S. Greig, "Inclusive education in international contexts," British Journal of Learning Support, vol. 30, no. 1, pp. 69-82, 2015.

[37] C. Boyle, K. Topping, and D. Jindal-Snape, "Teachers' attitudes towards inclusion in high schools," Teachers and Teaching, vol. 19, no. 5, pp. 527-542, 2013.

[38] R. L. Taylor, L. R. Smiley, and R. Ramasamy, "Effects of educational background and experience on teacher views of inclusion," Educational Research Quarterly, vol. 26, pp. 3-10, 2003.

[39] M. F. Tukov, The Education of Children with Special Needs in Cameroon: The Role of Teachers and Parents towards Inclusive Education, University of Oslo, Oslo, Norway, 2008.

[40] P. F. Shey, Parents Perspective on the Education of Children with Disabilities in Regular Schools in Cameroon, M.S. thesis, The University of Oslo, Oslo, Norway, 2003.

[41] C. O’Toole and N. Burke, "Ready, willing and able? Attitudes and concerns in relation to inclusion amongst a cohort of Irish pre-service teachers," European Journal of Special Needs Education, vol. 28, no. 3, pp. 239-253, 2013.

[42] K. Cotton, Principals and Student Achievement, Association for Supervision and Curriculum Development, Alexandria, VA, USA, 2003.

[43] D. King, "The changing shape of leadership," Educational Leadership, vol. 59, no. 8, pp. 61-63, 2002.

[44] R. Elmore, Building a New Structure for School Leadership, The Albert Shanker Institute, Washington, DC, USA, 2000.
[45] J. Spillane, R. Halverson, and J. Diamond, Toward a Theory of Leadership Practice: A Distributed Perspective, Institute for Policy Research, Evanston, IL, USA, 2000.

[46] M. Friend and W. D. Bursuck, Including Students with Special Needs, Allyn \& Bacon, Boston, MA, USA, 2nd edition, 1999.

[47] Inclusive Schools Network, 2015, http://inclusiveschools. org/category/resources/leadership-for-inclusive-schools/.

[48] T. P. Muffih, "SEEPD commended for spearheading inclusive education in NW Region," CBC Health Board Chronicle, vol. 3, no. 27, p. 2, 2011.

[49] R. P. Dolan and T. E. Hall, "Universal design for learning: implications for large scale assessment," IDA Perspectives, vol. 27, no. 4, pp. 22-25, 2001.

[50] D. Rose and A. Meyer, Teaching Every Student in the Digital Age: Universal Design for Learning, ASCD, Alexandria, VA, USA, 2002.

[51] D. Rose, S. Sethuraman, and G. Meo, "Universal design for learning," Journal of Special Education Technology, vol. 15, no. 2, pp. 26-60, 2000.

[52] D. D. Smith, Introduction to Special Education: Making a Difference, Allyn and Bacon, Boston, MA, USA, 6th edition, 2007.

[53] A. Mngo, "An investigation of the attitudes held by general education teachers toward students with disabilities in a pilot inclusive education program in Cameroon," Ph.D. thesis, ProQuest Dissertations and Theses database (UMI10273480), Andrews University, Berrien Springs, MI, USA, 2017. 


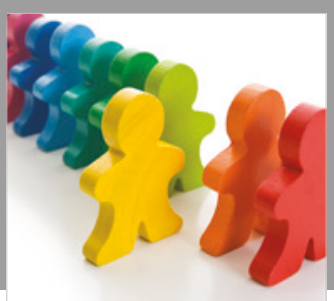

Autism

Research and Treatment
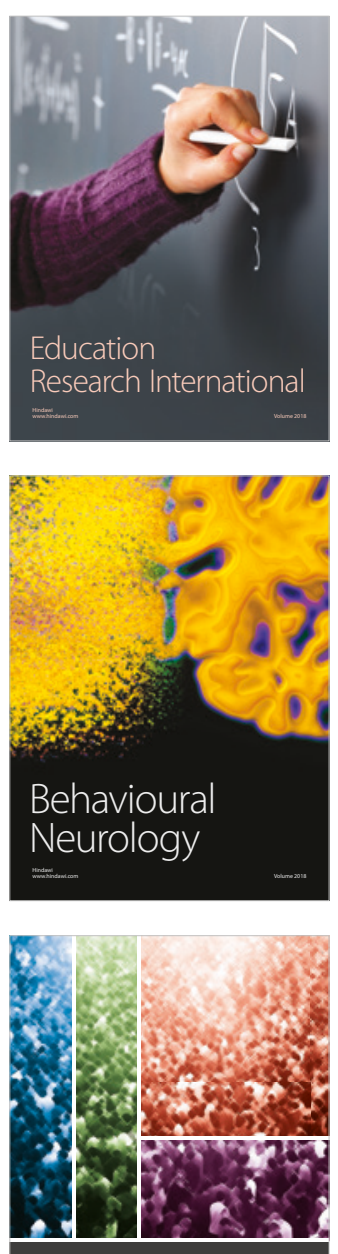

International Journal of

Population Research

$\underline{-m}$

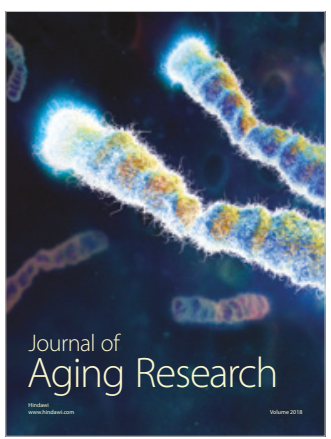

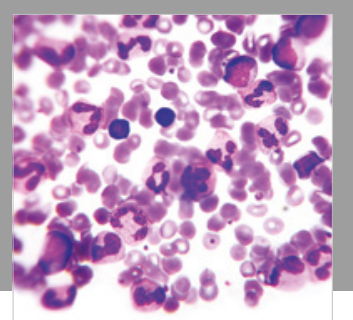

Pathology

Research International$$
=
$$

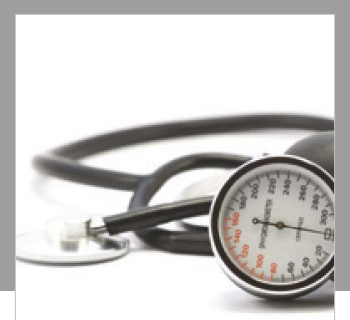

Nursing

Research and Practice

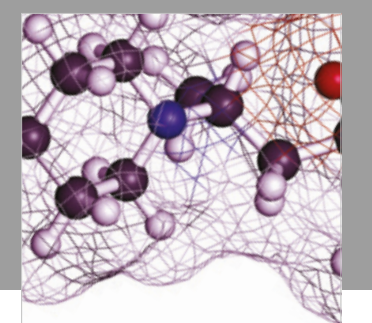

Pain

Research and Management

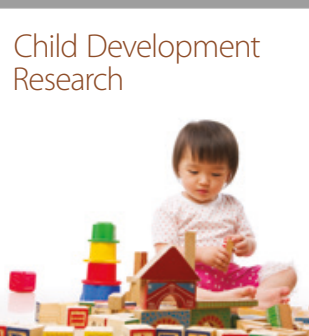

बाD

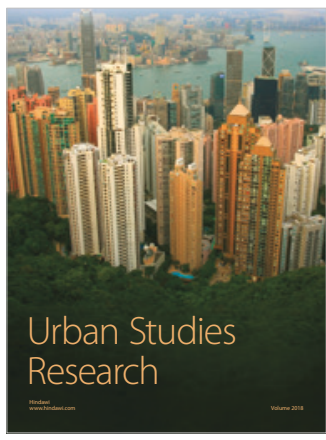

\section{Hindawi}

Submit your manuscripts at

www.hindawi.com
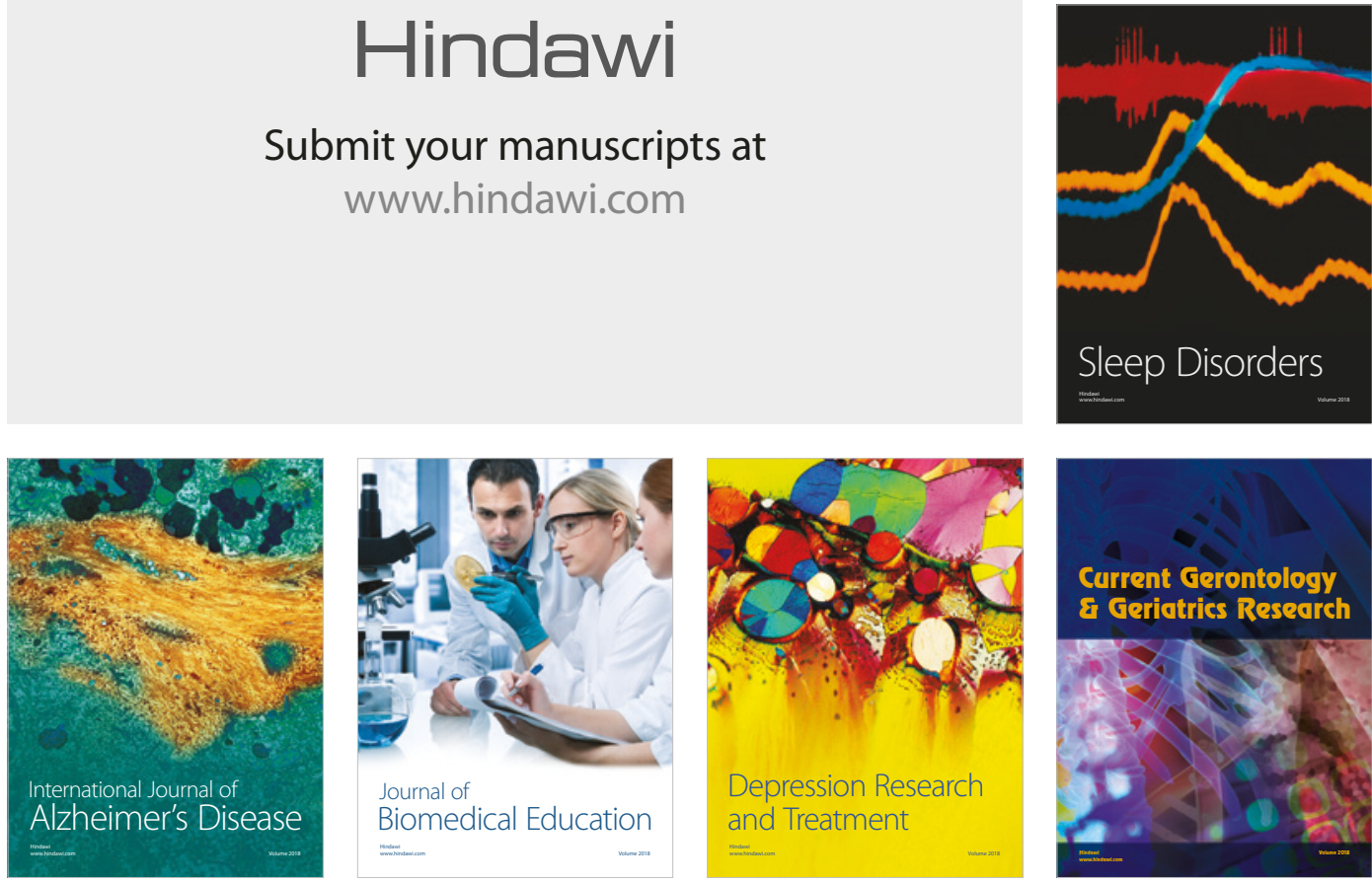

Journal of

Biomedical Education

$=$

smman

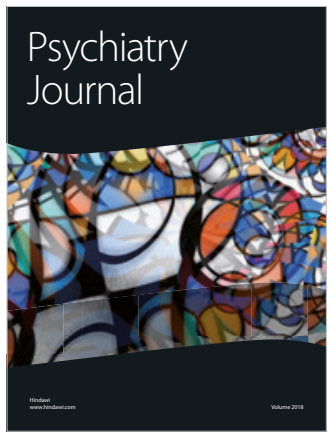

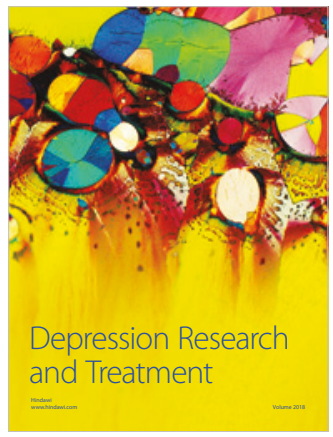
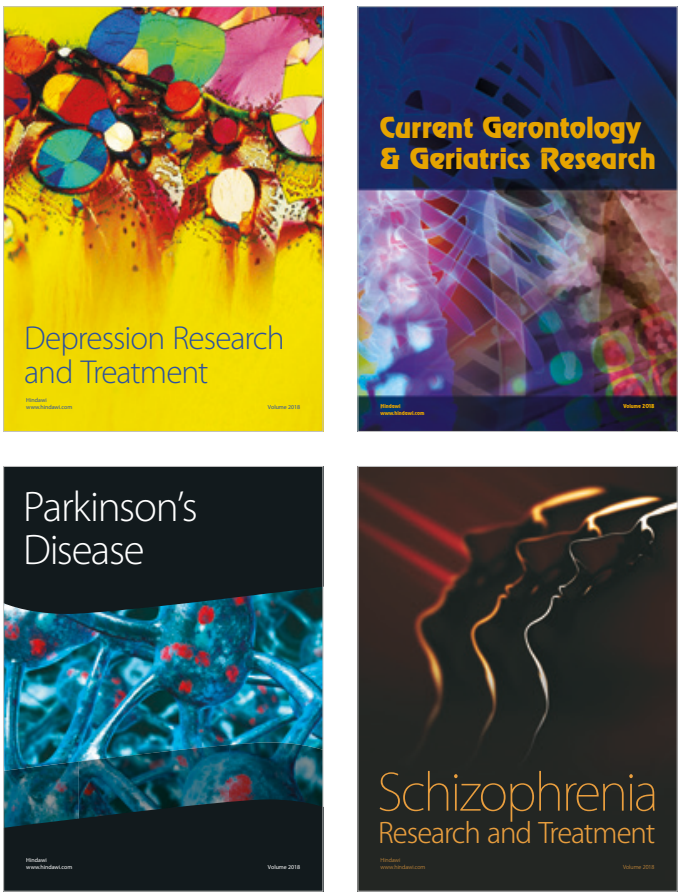